\title{
NGHIÊN CỨU ĐĂC ĐIỂM LÂM SÀNG, MÔ BÊNH HỌC VÀ ĐÁNH GIÁ KẾT QUẢ ĐIẾU TRỊ U TIỂU NÃO Ở TRÉ EM TẠI BỆNH VIỆN NHI TRUNG ƯởNG
}

Trân Văn Học ${ }^{1}$, Nguyễn Văn Thắng ${ }^{2}$, Nguyễn Thanh Liêm ${ }^{1}$

\section{TÓM TĂT}

U tiểu não là một trong nhũng u não thường gặp ở trẻ em, nếu phát hiện sớm và điều trị kịp thời đúng phác đồ sẽ kéo dài thời gian sống của trẻ. Nghiên cứu tiến cứu theo dõi dọc 124 bệnh nhân u tiểu não nhập viện trong 5 năm tại Bệnh viện Nhi Trung ương. Kết quả cho thấy tuổi mắc trung bình là 6,2, thuiơng gặp nhất từ 2 - 8 tuổi. Các triệu chứng lâm sàng tại thời điêm nhập viện: nôn 89,5\%, mất điều hòa động tác 89,5\%, loạng choạng 87,9\%, đau đầu 81,5\%, phù gai thị 54,4\%, giảm truơng lực co 33,9\%, run chi 32,3\%, các dấu hiệu khác ít gặp ...;

Đặc điểm mô bệnh học: U nguyên tủy bào 49,2\%, u tế bào hình sao 33,9\%, u màng não thất 13,7\%, các loại khác 3,2\%.

Kết quả điều trị: Tỷ lệ sống sau 5 năm đạt 38\%. Các di chứng ở bệnh nhân sống là rối loạn vận động, liệt dây thần kinh sọ, thay đổi tính nết, rối loạn thị lực, rối loạn ngôn ngũ.

Kết luận: Đặc điểm lâm sàng u tiểu não ở trẻ em là hội chứng tăng áp lực nội sọ và hội chứng tiểu não, mô bệnh học chủ yếu là u nguyên tủy bào và u tế bào hình sao. Có 38\% bệnh nhân sống sau 5 năm.

Tù̀ khóa: Đặc điểm lâm sàng, mô bệnh học, kết quả điều trị, u tiểu não ở trẻ em

Abstract

STUDY OF CLINICAL FEATURES, HISTOPATHOLOGY, ASSESSMENT OF TREATMENT OUTCOMES OF PEADIATRIC CEREBELLAR TUMORS AT THE VIETNAM NATIONAL CHILDREN'S HOSPITAL

Cerebellar tumor is one of the most common brain tumors in children, early detection and timely treatment will prolong survival for patients. A follow-up study of 124 patients with cerebellar tumors was hospitalized for 5 years at the Viet Nam National Children's Hospital.

\footnotetext{
${ }^{1}$ Bệnh viện Nhi Trung ương

${ }^{2}$ Trường Đại học Y Hà Nội
} 
The results show that the average age was 6.2, the most common age 2-8 years. Clinical manifestations include: vomiting $89.5 \%$, apraxia $89.5 \%$, ataxia $87.9 \%$, headache $81.5 \%$, papilledema $54.4 \%$, hypotonia $33.9 \%$, tremor $32.3 \%$, other signs are less common .....

Histopathological features: medulloblastoma 49.2\%, astrocytoma $33.9 \%$, ependymoma $13.7 \%$, other types $3.2 \%$.

Results of treatment: survival rate after 5 years was 38\%. The sequelae of living patients include movement disorders, cranial nerve paralysis, palpitations, visual disturbances, language disorders.

Conclusion: clinical features of cerebellar tumors are intracranial hypertension and cerebellar syndrome, the most histopathology are medulloblastoma and astrocytoma. There are 38\% of patient survive after 5 years.

Keywords: clinical features, histopathology, treatment outcome, cerebellar tumors in children.

\section{I. ĐẶT VẤN ĐỀ}

Các u não của hệ thân kinh trung ương chiếm khoảng $20 \%$ các khối tăng sinh ở trẻ em dưới 15 tuôii, trong đó u tiểu não chiếm hàng đầu về tỷ lệ mắc, chiếm 25 - 40\% tổng số u não trẻ em [1]. Về mô bệnh học, chủ yếu gồm ba loại là u nguyên tủy bào (medulloblastoma), u tế bào hình sao (astrocytoma), u màng não thất (ependymoma) và một số loại u khác hiếm gặp, như u đám rối mạch mạc phát triển từ đám rối mạch mạc, u tế bào mầm, u tổ chức biểu bì.... [2-4]. Ở Việt Nam, các nghiên cứu về u tiểu não còn chưa nhiêu. Năm 1989, Nguyễn Chương "Góp phần nghiên cứu chẩn đoán u tiểu não ở trẻ em" [5]. Năm 1996, Nguyễn Thị Quỳnh Hương "Đối chiếu lâm sàng và chụp cắt lớp vi tính $u$ tiểu não ở trẻ em" [6]. Các nghiên cứu này thực hiện trong điều kiện các phương tiện chẩn đoán và khả năng điêu trị u não ở nước ta còn gặp nhiêu khó khăn. Cho đến nay, chưa có nghiên cứu nào về u tiểu não ở trẻ em bổ sung cho hai nghiên cứu trên. Chính vì vậy chúng tôi thực hiện đề tài này với mục tiêu: $\boldsymbol{m} \hat{o}$ tả $\boldsymbol{m} \hat{o} \boldsymbol{t} t$ số đặc điêm lâm sàng, mô bệnh học và đánh giá kết quả điều trị u tiểu não trẻ em tại Bệnh viện Nhi Trung uoong.

\section{II. ĐỐI TỰ̂NG VÀ PHUONG PHÁP NGHIÊN CỨU}

\section{1. Đối tượng nghiên cứu}

Gồm 124 bệnh nhi được chẩn đoán u tiểu não nhập viện tại Bệnh viện Nhi Trung ương, được phẫu thuật và có kết quả mô bệnh học trong thời gian 5 năm (từ 1/1/2009 đến $31 / 12 / 2013)$. Sau đó tiếp tục được theo dõi đến 31/ 12/ 2016.

Độ tuổi bệnh nhân từ sau sinh đến 15 tuổi.

\subsection{Tiêu chuẩn chọn bệnh nhi}

Bệnh nhi được lựa chọn đủ tiêu chuẩn chẩn đoán u tiểu não và được phân loại u tiểu não theo mô bệnh học:

\section{Lâm sàng:}

- Hội chứng tăng áp lực sọ não: đau đâu và nôn, có thể kèm theo phù gai thị giác.

- Hội chứng rối loạn chức năng thân kinh liên quan vị trí khối u: dáng đi loạng choạng, rối loạn phối hợp động tác. 
Cận lâm sàng:

- Hình ảnh khối u tiểu não hoặc vùng tiểu não trên chụp cộng hưởng từ.

- Khối u của bệnh nhân được phân loại theo mô bệnh học (sau khi phẫu thuật).

\subsection{Phương pháp nghiên cứu}

Nghiên cứu mô tả tiến cứu theo dõi dọc một loạt các ca bệnh.

Trong 5 năm có 124 bệnh nhân u tiểu não được phẫu thuật và có xác định mô bệnh học. học.

Xử lý số liệu trên phần mềm thống kê y

\section{Biểu đồ 1. Phân bố theo tuổi và giới}

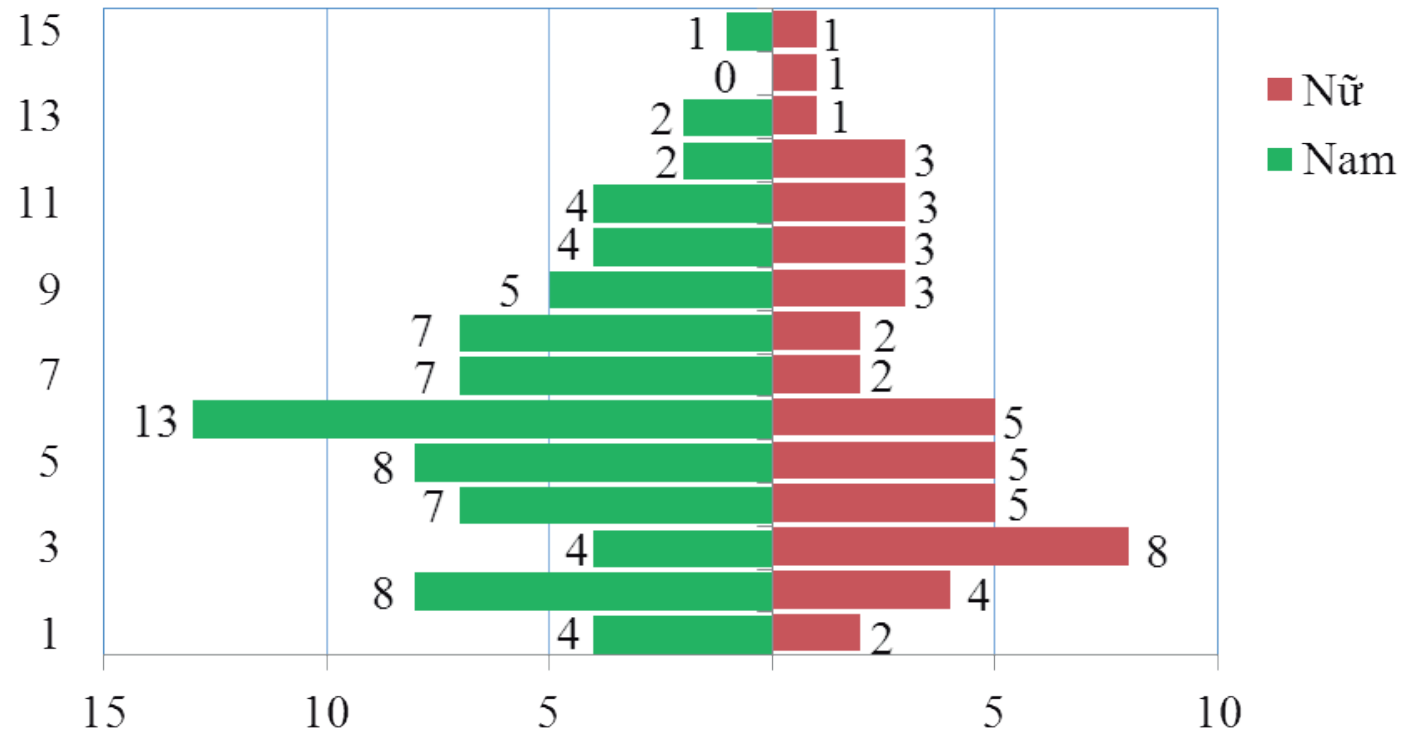

U tiểu não trẻ em gặp ở tất cả các lúa tuổi, trong đó nhóm tù 2 - 8 tuổi là phổ biến 85 bệnh nhân (68,5\%), nam mắc nhiều hơn nữ ở phần lớn các lúa tuổi.

Bảng 1. Các triệu chứng lâm sàng tại thời điểm nhập viện.

Triệu chứng

Nôn

Mất điều hòa động tác

Loạng choạng

Đau đầu

Phù gai thị $(n=114)$

Giảm trương lực cơ

\section{KẾT QUẢ NGHIÊN CỨU}

\section{1. Đặc điểm lâm sàng và mô bệnh học}

Một số đặc điểm dịch tễ học lâm sàng

Trong thời gian từ $1 / 1 / 2009$ đến 31/12/2013, chúng tôi khám và điêu trị 124 bệnh nhân u tiểu não. Tuổi trung bình: $6,2 \pm$ 3,4. Nhỏ nhất: 4,5 tháng, lớn nhất: 15 tuổi. Tỷ lệ nam:nũ $=1,58: 1$. Các bệnh nhân được chẩn đoán dựa trên lâm sàng, hình ảnh chụp cộng hưởng từ sọ não và phẫu thuật cắt $\mathrm{u}$ có phân loại u theo mô bệnh học. 


\begin{tabular}{cc} 
n & Tỷ lệ (\%) \\
\hline 40 & 32,3 \\
36 & 29,0 \\
26 & 21,0 \\
22 & 17,7 \\
19 & 15,3 \\
\hline
\end{tabular}

Rung giật nhãn câu Trong tăng áp lực nội sọ nôn và đau đâu là thuiờng gặp nhất (với 89,5\% và 81,5\%). Rối loạn
ức năng tiểu não nồi bật nhất là mất điêu hòa động tác và loang choang thuiờng găp (với 89,5\% và $87,9 \%)$.

\section{Biểu đồ 2. Phân bố u tiểu não theo đặc điểm mô bệnh học}

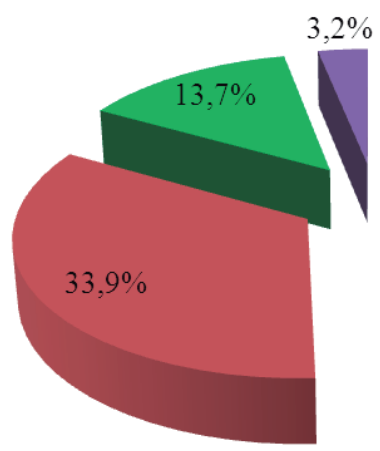

$$
\begin{aligned}
& \text { U nguyên tủy bào } \\
& \text { U tế bào hình sao } \\
& \text { - U màng não thất } \\
& \text { - Các loại u khác }
\end{aligned}
$$

$49,2 \%$

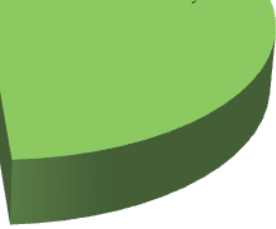

Bệnh nhân u nguyên tủy bào chiếm tỷ lệ cao nhất (gân 50\%), sau đó là u tế bào hình sao, u màng não thất.

\section{2. Đánh giá kết quả điêu trị}

\section{Biểu đồ 3. Đường Kaplan - Meier}

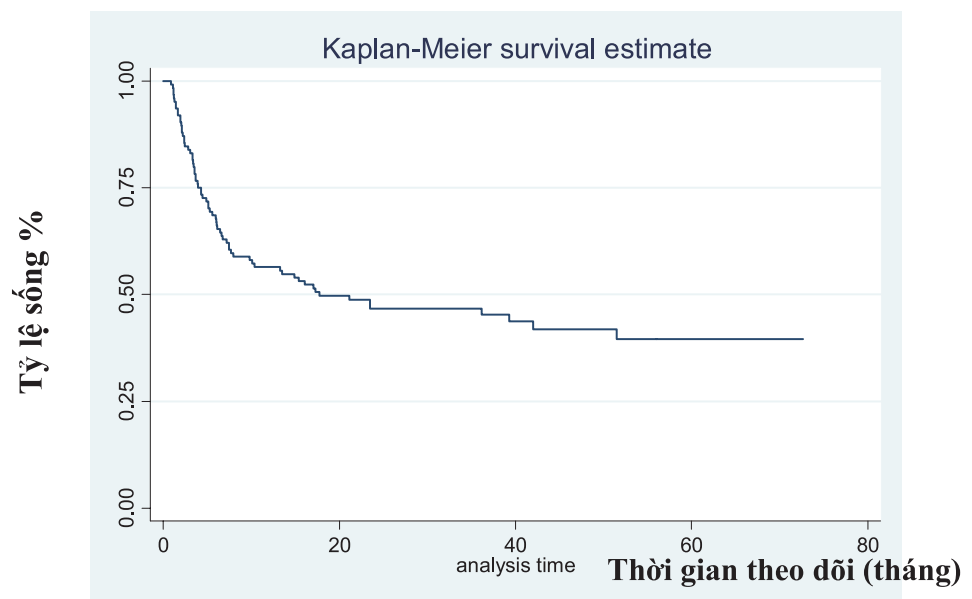

Ước đoán số bệnh nhân sống được sau 5 năm đạt 38\%. 
Bảng 2. Các chứng của những bệnh nhân sống

\section{Loại di chứng}

N (55)

16

9

6

5

2

Tỷ lệ (\%)

29,1

16,5

Thay đổi tính nết

10,9

Rối loạn thị lực

9,1

Rối loạn ngôn ngữ

Di chứng nhiêu nhất là rối loạn vận động (chiếm gân 1/3 bệnh nhân).

\section{BÀN LUÂ̂N}

\section{1. Đặc điểm lâm sàng và mô bệnh học}

Tính thuiơng gặp

Nghiên cứu từ $1 / 1 / 2009$ đến $31 / 12 / 2013$ có 124 trường hợp được phân loại mô bệnh học, chiếm 43,6\% tổng số bệnh nhân u não được khám và điều trị tại Bệnh viện Nhi Trung ương.

\section{Tuổi và giới}

Biểu đồ 1 trong nghiên cứu chỉ ra u tiểu não gặp ở các lứa tuổi, trong đó nhóm $2-8$ tuổi là phổ biến nhất. Tuổi trung bình mắc bệnh là $6,2 \pm 3,4$ tuổi, chúng tôi gặp trẻ mắc bệnh thấp nhất là 4,5 tháng tuổi. Trẻ nam mắc bệnh nhiều hơn trẻ nữ (theo tỷ lệ 1,58:1).

Một nghiên cứu của Peter Kaatsch và cs tại cộng đồng ở Đức với cỡ mẫu lớn 3268 trẻ dưới 15 tuổi mắc bệnh u não từ năm 1990 1999, cho thấy u tiểu não mắc khá cao (chiếm $27,9 \%$ tổng số), trong đó trẻ dưới 6 tuổi và 5 - 9 tuổi chiếm tỷ lệ cao nhất $(9,3-9,7 /$ 1.000.000 dân), nhưng giảm hơn ở lứa tuổi 10 - 14 tuổi và 15 - 19 tuổi $(5,7$ - 3,7/ 1.000.000 dân) [7]. Về giới tính của trẻ mắc u tiểu não nói chung, theo các tác giả ngoài nước, trẻ nam thường mắc cao hơn trẻ nữ với các tỷ lệ khác nhau từ $1,1 / 1$ đến $1,45 / 1[1,2,7]$.

\section{Đặc điểm lâm sàng}

Bảng 1 cho thấy tần suất các triệu chứng lâm sàng ở thời điểm nhập viện. Dấu hiệu tăng áp lực nội sọ nổi bật là hai triệu chứng nôn $111(89,5 \%)$ và đau đầu 101 trẻ $(81,5 \%)$, sau đó là phù gai thị $62(54,4 \%)$. Các triệu chứng rối loạn chức năng tiểu não nổi bật là mất điều hòa động tác 111 (89,5\%) và loạng choạng 109 (87,9\%).

Các nghiên cứu lâm sàng $u$ tiểu não trước đây, Nguyễn Chương (1989) thấy đau đầu $82,7 \%$, nôn $72,4 \%$, phù gai thị $61 \%$ ở 29 bệnh nhân u tiểu não [5]. Packer R.J và cs (2002) nhận thấy u dưới lều tiểu não $84 \%$ trường hợp có nôn, $82 \%$ đau đâu, loạng choạng $72 \%$, rung giật nhãn câu $46 \%$, nhìn đôi có $29 \%$ trường hợp [4].

Nghiên cứu của chúng tôi về các triệu chứng của hai hội chứng tăng áp lực nội sọ và rối loạn chức năng tiểu não đều có kết quả và nhận xét tương đương các tác giả khác trong và ngoài nước.

\section{2. Đặc điểm mô bệnh học của khối u tiểu não}

Tỷ lệ mắc bệnh của u tiểu não theo mô bệnh hoc

Tỷ lệ mắc bệnh u tiểu não theo mô bệnh học tại Biểu đồ 2 cho thấy u nguyên tủy bào chiếm tỷ lệ cao nhất: 61 bệnh nhân $(49,2 \%)$, sau đó đến u tế bào hình sao: 42 (33,9\%), u màng não thất có tỷ lệ thấp nhất trong ba loại chính: 17 (13,7\%), chỉ có ít các loại u khác: 4 $(3,2 \%)$. Các kết quả của Gjerris tương đương 
là: $47,5 \%, 34,1 \%, 13,9 \%$ và $4,5 \%$, của Chang là: $50,5 \%, 29,5 \%, 13,3 \%$ và $6,7 \%$. Như vậy kết quả nghiên cứu của chúng tôi phù hợp với các nghiên cứu của Gjerris (1988) và Chang (1993) [2-3].

\subsection{Nhân xét kết quả điêu trị}

Tình hình chung bệnh nhân sống và tử vong

Đường Kaplan-Meier ở biểu đô 3 , ước tính khả năng sống sau 5 năm cho tất cả 124 bệnh nhân u tiểu não là $38 \%$. So sánh với nghiên cứu của Copeland tại Houston (Hoa Kỳ) khả năng sống sau 5 năm ở những bệnh nhân u tiểu não là $60 \%$ [8], kết quả của chúng tôi còn thấp hơn.

Các di chuing thường gặp ở bệnh nhân còn sống

Theo bảng 2, trong 55 bệnh nhân còn sống có $29,1 \%$ có rối loạn vận động, $16,5 \%$ liệt thần kinh sọ, 10,9\% thay đổi tính nết, 9,1\% rối loạn thị lực, 3,6\% rối loạn ngôn ngữ. Nghiên cứu của Tycho và cs (2008) qua theo dõi 31 bệnh nhân u tế bào hình sao tiểu não độ ác tính thấp có di chứng về thần kinh là $43 \%$, số có giảm sút học tập là $19 \%$, số có thay đổi về hành vi và tình cảm là $27 \%$, tuy vậy $100 \%$ tự thực hiện được các công việc cá nhân hàng ngày và cảm thấy hài lòng với chất lượng cuộc sống của bản thân [9].

\section{KẾT LUẬN}

Nghiên cứu 124 trẻ em bị u tiểu não tại Bệnh viện Nhi Trung ương từ năm 2009 đến 2014, chúng tôi rút ra một số kết luận sau:

\section{Đặc điểm lâm sàng, mô bệnh học $u$ tiểu não ở trẻ em}

- Tuổi mắc bệnh trung bình: 6,2. Nam mắc bệnh nhiêu hơn nữ theo tỷ lệ là 1,58/1.

- Biểu hiện lâm sàng chung là nôn $89,5 \%$, đau đầu $81,5 \%$, phù gai thị $54,4 \%$, mất điêu hòa động tác $89,5 \%$, loạng choạng $87,9 \%$, run chi $32,3 \%$.

- Mô bệnh học: u nguyên tủy bào chiếm $49,2 \%$, u tế bào hình sao $33,9 \%$, u màng não thất 13,7\%, các loại u khác ít gặp 3,2\%.

\section{Đánh giá kết quả điêu trị}

- Kết quả điêu trị chung: số bệnh nhân còn sống sau 5 năm là $38 \%$.

- Các di chứng có thể gặp ở bệnh nhân sau điều trị bao gôm: rối loạn vận động, liệt dây thần kinh sọ, thay đổi tính nết, rối loạn thị lực và rối loạn ngôn ngữ.

Kiến nghị: Cần nghiên cứu sâu hơn nữa về các phác đô điều trị, tiên lượng bệnh và đột biến gien của từng loại u theo mô bệnh học

Lời cảm ơn: Chúng tôi xin chân thành cảm ơn các thành viên nhóm nghiên cứu $U$ não, khoa Thân kinh, khoa Ung bướu, khoa Chẩn đoán hình ảnh và các khoa liên quan đã giúp đỡ và hỗ trợ nghiên cứu này. 


\section{TÀI LIỆU THAM KHẢO:}

1. Pollack I.F (1994). "Brain tumours in children”. N Engl J Med, 331: 1500-7.

2. Gjerris F, Agerlin N, Borgesen S.E et al (1998). Epidemiology and prognosis in children treated for intracranial tumours in Denmark 1960 - 1984. Child's Nervous System. Issue 14, page 302-11.

3. Chang T (1993). "Posterior Cranical fossa tumour in childhood". Neuroradiology: 35 (4), 274 - 8.

4. Roger J. Packer, Henry S. Friedman, Larry E. Kun and Gregory N. Fuller (2002). "Tumors of the brain stem, cerebellum and fourth ventricle", Neuro-oncology, chapter 6, $171-192$.

5. Nguyễn Chương (1989). Góp phần nghiên cứu vấn đề chẩn đoán u tiểu não trẻ em, Luận án phó tiến sĩ y học, Đại học Y Hà Nội.

6. Nguyễn Thị Quỳnh Hương (1996). Đối chiếu lâm sàng và chụp cắt lớp vi tính u tiểu não trẻ em. Luận văn Thạc sĩ y học, Trường Đại học Y Hà Nội.

7. Peter Kaatch, Christian H. Rickert, Joanchim Kuhl et al (2001). "Population - based epidermiologic data on brain tumours in German children". Cancer, Volue 92, Issue 12, Pages 3155-14.

8. Donna R. Copeland, Carl deMoor, Bartlett D. Moore, et al (1999). Neurocognitive Development of Children After a Cerebellar Tumor in Infancy: A Longitudinal Study, Journal of Clinical Oncology, 17 (11), 3476-86.

9. Tycho J. Z, Andrea P, Barbara D, et al (2008). Outcome of children with low - grade cerebellar astrocytoma: long-term complications and quality of life, Childs Nerv Syst, 24, $1447-55$. 